\title{
Prevalent abnormal prion protein in human appendixes after bovine spongiform encephalopathy epizootic: large scale survey
}

\author{
(c) $(1)$ (8)
}

\begin{abstract}
O Noel Gill head of department ${ }^{1}$, Yvonne Spencer head of pathology ${ }^{2}$, Angela Richard-Loendt senior research histologist ${ }^{3}$, Carole Kelly senior CJD scientist ${ }^{1}$, Reza Dabaghian senior scientific and technical manager ${ }^{4}$, Lynnette Boyes histologist ${ }^{3}$, Jacqueline Linehan senior research histologist ${ }^{5}$, Marion Simmons veterinary research pathologist, head of EU Reference Laboratory for TSE ${ }^{2}$, Paul Webb pathology research scientist ${ }^{2}$, Peter Bellerby pathology research scientist ${ }^{2}$, Nick Andrews senior statistician ${ }^{1}$, David A Hilton consultant neuropathologist ${ }^{6}$, James W Ironside professor of clinical neuropathology ${ }^{7}$, Jon Beck research scientist ${ }^{5}$, Mark Poulter research scientist ${ }^{5}$, Simon Mead reader in neurology, consultant neurologist ${ }^{5}$, Sebastian Brandner professor of neuropathology, honorary consultant neuropathologist ${ }^{3}$
\end{abstract}

${ }^{1}$ HIV and STI Department, and CJD Section, National Centre for Infectious Disease Surveillance and Control, Public Health England, London, UK; ${ }^{2}$ Pathology Unit, Science Directorate, Animal Health and Veterinary Laboratories Agency, Addlestone, Surrey, UK; ${ }^{3}$ Division of Neuropathology, the National Hospital for Neurology and Neurosurgery, and Department of Neurodegenerative Disease, UCL Institute of Neurology, Queen Square, London, WC1N 3BG, UK; ${ }^{4}$ Virus Reference Department, Public Health England, London, UK; ${ }^{5} \mathrm{MRC}$ Prion Unit and Department of Neurodegenerative Disease, UCL Institute of Neurology, Queen Square, London, UK; ${ }^{6}$ Department of Cellular and Anatomical Pathology, Derriford Hospital, Plymouth, UK; ${ }^{7}$ National Creutzfeldt-Jakob Disease Research and Surveillance Unit, School of Molecular and Clinical Medicine, University of Edinburgh, Edinburgh, UK

\begin{abstract}
Objectives To carry out a further survey of archived appendix samples to understand better the differences between existing estimates of the prevalence of subclinical infection with prions after the bovine spongiform encephalopathy epizootic and to see whether a broader birth cohort was affected, and to understand better the implications for the management of blood and blood products and for the handling of surgical instruments.

Design Irreversibly unlinked and anonymised large scale survey of archived appendix samples.

Setting Archived appendix samples from the pathology departments of 41 UK hospitals participating in the earlier survey, and additional hospitals in regions with lower levels of participation in that survey.
\end{abstract}

Sample 32441 archived appendix samples fixed in formalin and
embedded in paraffin and tested for the presence of abnormal prion
protein (PrP).
Results Of the 32441 appendix samples 16 were positive for abnormal
PrP, indicating an overall prevalence of 493 per million population (95\%
confidence interval 282 to 801 per million). The prevalence in those born
in $1941-60$ (733 per million, 269 to 1596 per million) did not differ
significantly from those born between 1961 and 1985 ( 412 per million,
198 to 758 per million) and was similar in both sexes and across the
three broad geographical areas sampled. Genetic testing of the positive
specimens for the genotype at PRNP codon 129 revealed a high
proportion that were valine homozygous compared with the frequency
in the normal population, and in stark contrast with confirmed clinical

Correspondence to: S Brandner s.brandner@ucl.ac.uk

Extra material supplied by the author (see http://www.bmj.com/content/347/bmj.f5675?tab=related\#webextra)

Supplementary information, tables, and figure captions

Description of procedure for processing blocks

Supplementary figure 1

Supplementary figure 2

Supplementary figure 3 
cases of vCJD, all of which were methionine homozygous at $P R N P$ codon 129.

Conclusions This study corroborates previous studies and suggests a high prevalence of infection with abnormal PrP, indicating vCJD carrier status in the population compared with the 177 vCJD cases to date. These findings have important implications for the management of blood and blood products and for the handling of surgical instruments.

\section{Introduction}

Variant Creutzfeldt-Jakob disease (vCJD) in the United Kingdom and some other countries ${ }^{12}$ was caused by an exposure of the population to bovine spongiform encephalopathy (BSE) prions. Large numbers of the UK population were exposed to BSE prions in the late 1980s and early 1990s through contaminated meat products in the food chain. vCJD differs from other forms of Creutzfeldt-Jakob disease in that abnormal prion protein $(\mathrm{PrP})$ has been detected in tonsil biopsy tissues before death and throughout the lymphoreticular system and some other tissues after death. ${ }^{3}$ Accumulation of abnormal PrP in follicular dendritic cells of lymphoreticular tissue is thought to precede invasion of the central nervous system, and previous observations ${ }^{45}$ have confirmed the presence of abnormal PrP in archived surgical samples removed before the development of clinical symptoms. Although there have been only 177 cases of vCJD to date in the United Kingdom, it is likely that subclinical carrier states of infection with vCJD prions exist, particularly on crossing a species barrier after widespread low dose exposure. ${ }^{6-9}$

In the United Kingdom, four prevalence surveys of abnormal PrP have been reported to date ${ }^{510-12}$ (see supplementary table

1). In the face of continued uncertainty over the results of these surveys, in 2008 the Spongiform Encephalopathy Advisory Committee (SEAC (replaced in 2011 by the TSE Risk Assessment Subgroup of the Advisory Committee on Dangerous Pathogens) advised a second immunohistochemistry survey of archived appendix samples to increase understanding of the differences between existing estimates of the prevalence of subclinical abnormal prion infection and to see whether a broader birth cohort was affected. This paper reports on the findings of that second survey.

\section{Methods}

\section{Sample collection, anonymisation, and data handling}

To screen at least 30000 satisfactory appendix samples from the 1941-60 and the 1961-85 birth cohorts, the Health Protection Agency (since 1 April 2013 part of Public Health England) collected 40000 samples that had been removed at operations between 2000 and 2012. The source appendix tissue, archived in standard histology wax blocks (formalin fixed, paraffin embedded) in 41 participating hospitals (see supplementary table 4), was sent to Public Health England. Many of the collaborating hospitals had participated in the earlier appendix and tonsil survey ${ }^{5}$ by providing samples from appendectomies before 2000 and agreed to provide additional samples. To improve geographical representation of samples, we contacted additional hospitals in regions with lower levels of participation in the earlier survey, and collaboration was sought from the heads of the histopathology departments.

At Public Health England, we selected a single block per case and forwarded blocks in collections ("bins") of 50 source appendix samples to the two collaborating prion screening laboratories, at University College London Institute of
Neurology and the Animal Health and Veterinary Laboratories Agency, where sectioning, staining, and expert microscopic examination was conducted. After quality assessment of the sectioning and staining, each bin of samples was returned to the laboratory at Public Health England. Before permission was given to the screening laboratories to begin examination we completed a robust, irreversible unlinking and anonymisation procedure (fig $1 \Downarrow$ ). At the Public Health England coordinating laboratory, we created a survey database that included the survey number, sex of the case, five year birth cohort, and broad geographical area where the original appendicectomy hospital was sited (fig 1 , table $1 \Downarrow$ and supplementary table 4 ). We calculated exact binomial confidence intervals for the prevalence estimates and compared prevalence between subgroups using Fisher's exact test with a 5\% significance level.

\section{Preparation of sections and immunohistochemical detection of abnormal PrP}

From each paraffin block we cut a primary set of three sections. We detected abnormal PrP using mouse monoclonal antiPrP antibodies KG9 on one section and ICSM35 ${ }^{10}{ }^{12}{ }^{13}$ on another (see supplementary methods), visualised using a peroxidase-diaminobenzidine detection kit (DAB Map Ventana Medical System; Roche, Burgess Hill, UK) (fig 2 A-D, F-I $\Downarrow$ ). To investigate suspect cases and confirm positive ones, we repeated the staining on additional, subsequent sections and with antiPrP monoclonal antibodies $(3 \mathrm{~F} 4$ and $12 \mathrm{~F} 10$, see supplementary methods) (fig 2 P-S). Both laboratories used identical equipment (Ventana Discovery XT; Roche, Burgess Hill, UK), reagents, and protocols. We also stained half of the samples with haematoxylin and eosin to assess the proportion affected by inflammation. We assessed each section set to ensure the presence of five or more follicles and whether the tissue contained appendix biopsy tissue or other tissue that may have been collected in error. In addition to the appendix samples, we occasionally identified non-appendix tissue containing lymphoid follicles and we included this tissue when it met the criteria. From any samples with possible follicular immunoreactivity, we prepared 12 additional $4 \mu \mathrm{m}$ sections and three $10 \mu \mathrm{m}$ paraffin rolls (fig 1). To determine how the presence of florid granulocytic (purulent) inflammation affected the detection of follicular dendritic cells in secondary follicles, appendixes that met the inclusion criteria ( $\geq 5$ follicles present), in particular where follicles were partially overrun by granulocytes, we carried out CD21 immunostaining - an established marker for follicular dendritic cells ${ }^{14}$ —on five samples each with minimal, moderate, or severe inflammation (see supplementary fig 1).

\section{Expert examination}

Once irreversibly anonymised, expert examination at UCL Institute of Neurology (SB) or the Animal Health and Veterinary Laboratories Agency (MMS/YS) categorised samples as either positive, suspect, non-specific, or negative. A positive sample showed immunolabelling of a characteristic follicular dendritic cell network within a germinative centre of a follicle and at least one follicle had to contain a small network of immunopositive follicular dendritic cells. The positive follicular dendritic cells had to be present either in consecutive sections in the same follicle, or in a different follicle on a deeper section. A suspect sample had either weak immunoreactivity in a follicle that did not correspond to the typical pattern of PrP positive follicular dendritic cell, or weak, equivocal reactive staining that was not reproducible on consecutive sections (fig $3 \mathrm{~K}, \mathrm{M} \Downarrow$ ). Specimens classified as non-specific showed antibody binding in the follicle 
centres-for example, in degraded tissue that did not show typical follicular dendritic cell morphology (fig $3 \mathrm{~J}, \mathrm{~L}, \mathrm{~N}$ ). Negative samples showed no immunoreactivity; specific labelling of non follicular dendritic cell structures within follicles, such as macrophages; non-specific (background) labelling inside the follicles; or labelling of structures outside the follicles (see supplementary fig 1). We then referred all section sets of interest (positive and suspect immunolabelling) to other experts (JWI and DH) for two independent repeat examinations, including staining of spare sections at the National CJD Research and Surveillance Unit (fig 3 C). Finally, at three meetings the expert histopathologists reviewed each written report and slide set to arrive at a consensus opinion of the findings.

\section{Determination of PRNP codon 129 genotype}

We determined the codon 129 genotype of positive samples and a selection of others using allele discrimination with minor groove binding probes. For primary assay, we used a reverse transcription polymerase chain reaction, which was confirmed with a polymerase chain reaction based restriction endonuclease analysis (see supplementary methods).

\section{Results}

\section{Material examined and exclusion of unsuitable specimens}

A total of 40022 paraffin wax blocks were processed in 801 bins; 20041 at UCL Institute of Neurology and 19981 at the Animal Health and Veterinary Laboratories Agency. Overall, 80044 immunolabelled slides underwent initial assessment. In addition, 5720 control sections and approximately 4000 repeat sections $(5 \%)$ were assessed. From the 40022 appendix specimens collected, $19 \%$ (7500 samples) were rejected because either no viable follicles were present, the follicles were overrun or destroyed by inflammation, fewer than five follicles were present, or the tissue was atrophied. The rejection rate varied between the sample bins, from zero in 50 (six bins) to 29 in 50 (one bin). Altogether, 1995 repeat sections were made usually because of machine failures (54\%), incomplete dewaxing (14\%), or peroxidase-diaminobenzidine debris $(12 \%)$ (see supplementary table 3 ).

\section{Detection of abnormal PrP in appendix samples and distribution of PRNP codon 129 genotypes}

The survey included appendixes from operations conducted between 2000 and 2012. Of the 32441 appendixes included, 16 met the criteria for being positive; selected sections for nine of these 16 appendixes are shown (fig 3 A-I). The number of positive follicles, the size of the affected follicular dendritic cell area, and the strength of the immunolabelling, varied between these 16 samples (for example, fig $2 \mathrm{U}-\mathrm{Y}$; table 1), and positive labelling was always confined to the follicular dendritic cells in germinative centres of the secondary follicles. Another two appendix samples met the criteria for being suspect (fig $3 \mathrm{~K}$, M; table 1). Nine samples showed non-specific antibody binding in the follicle centre, owing to necrotic degradation of the appendix as a result of appendicitis (for example, fig $3 \mathrm{~J}, \mathrm{~L}, \mathrm{~N}$ ). The remaining samples were classified as negative.

Of the 16 positive appendix samples, eight were methionine homozygous at PRNP codon 129, four methionine-valine heterozygous, and four valine homozygous (table 1). One of the two suspect appendixes was methionine-valine heterozygous and the other was valine homozygous. Transverse and longitudinal sections were available in the 16 positive appendixes (table 1). Positive follicles were not uniformly distributed but showed an irregular distribution with strong labelling in several adjacent follicles on one cross section (fig 2 U-Y), and fewer or no positive follicles on a different transverse or longitudinal level. Between $2 \%$ and $20 \%$ of follicles present, in all available sections, were positive in five of the 16 positive samples (the codon 129 genotype was methionine homozygous in three, and methionine-valine heterozygous and valine homozygous in the others); between $25 \%$ and $60 \%$ in seven samples (three methionine homozygous, two methionine-valine heterozygous, and two valine homozygous) and $75 \%$ to $89 \%$ in four samples (two methionine homozygous, one methionine-valine heterozygous, and one valine homozygous). Thus the morphology, staining intensity, distribution, and proportion of positive follicles (fig 3 ) were independent of the codon 129 genotype (table 1).

\section{Difference between antibodies used in this study}

Strong labelling was usually produced by antiPrP antibody ICSM35 (fig 2 A, B), whereas antiPrP antibody KG9 generally showed weaker immunoreactivity in the same follicles on immediately adjacent sections (fig $2 \mathrm{~F}, \mathrm{G}$ ), in contrast with sporadic Creutzfeldt-Jakob disease brain sections, where both antibodies showed identical signals (fig $2 \mathrm{C}, \mathrm{D}, \mathrm{H}, \mathrm{I}$ ). Application of different retrieval methods for the positive appendix samples, such as longer microwaving or autoclaving, or formic acid pretreatment, did not increase KG9 immunoreactivity. Having observed the difference between ICSM35 and KG9 on the initial positive appendixes, we further applied well established diagnostic antibodies 3F4 and 12F10 15 to sections adjacent to any positively labelled sections, and again immunolabelling generally was weaker or undetectable (for example, fig $2 \mathrm{~K}, \mathrm{~L}, \mathrm{P}, \mathrm{Q}$ ). All four antibodies yielded a strong signal on brain sections (fig $2 \mathrm{C}, \mathrm{H}, \mathrm{M}, \mathrm{R}$ and $\mathrm{D}, \mathrm{I}, \mathrm{N}, \mathrm{S}$ ) and formic acid treated tonsil biopsy samples from $\mathrm{VCJD}$ cases (fig $2 \mathrm{E}, \mathrm{J}, \mathrm{O}, \mathrm{T})$.

\section{Follicular dendritic cells degradation in inflamed appendixes}

Robust CD21 immunolabelling of follicular dendritic cell was seen in all follicles in appendixes with no or minimal granulocyte infiltration (see supplementary fig $1 \mathrm{~A}-\mathrm{C}$ ), whereas fewer CD21 positive follicular dendritic cells were seen in moderately inflamed appendixes (see supplementary fig $1 \mathrm{D}-\mathrm{F}$ ) and none in severely inflamed appendixes, where follicles were overrun by inflammatory cells (see supplementary fig 1 G-I). This indicates that the exclusion of inflamed appendixes from the survey samples was justified, as no PrP immunolabelled follicular dendritic cell would have been detectable.

\section{Prevalence of abnormal PrP by birth cohort, sex, and geographical area}

The observed prevalence of abnormal PrP was 493 per million population overall (table $2 \Downarrow$ ). The prevalence of 733 per million (95\% confidence interval 269 to 1596 per million) seen in those born in 1941-60 was not significantly different from the 412 per million (198 to 758 per million) seen in those born between 1961 and 1985. When these two birth cohorts were subdivided into nine birth cohorts (1941-45, 1946-50, etc), there was at least one positive appendix in each cohort apart from the 1961-65 cohort (table 2). Although 10 of the positive appendixes 
had been collected from men and six from women, the difference was not statistically significant. When the samples collected from 41 hospitals throughout England (see supplementary table 4) were grouped into three broad geographical areas (north east and north west; south east coast, south west, and London; and East and West Midlands), there were no apparent geographical differences in abnormal prion prevalence. Because all the survey appendixes were collected from operations conducted between 2000 and 2012, and the previous operative history of the 177 vCJD cases in the United Kingdom is known, it can be concluded that none of the positive appendixes came from known vCJD cases.

\section{Discussion}

In 32441 formalin fixed paraffin embedded appendix samples, we found 16 specimens positive for abnormal prion protein $(\operatorname{PrP})$, indicating a prevalence of 493 per million population overall, and it was similar in both sexes and across the three broad geographical areas sampled.

Although the overall prevalence estimate, 493 per million ( $95 \%$ confidence interval 282 to 801 per million), was double the point estimate measured in the earlier survey of appendixes (237 per million, 49 to 692 per million), ${ }^{5}$ the estimated prevalence range largely overlapped that from the first survey but was narrower with a higher central estimate (1:2000 $v$ 1:4000). The current survey also shows the presence of PrP across a wider birth cohort than found previously.

\section{Genotypes of positive appendix samples}

A striking finding of the first appendix survey was the presence of the valine homozygous genotype at PRNP codon $129^{17}$ in two of the three positive samples. The present, larger study gives a more representative picture of the frequency of genotypes and the variation of immunolabelling in these positive appendixes: $50 \%$ of the 16 positive samples were methionine homozygous at PRNP codon 129, 25\% methionine-valine heterozygous, and $25 \%$ valine homozygous, in contrast with the normal distribution in the population of $43 \%, 45 \%$, and $13 \%$, respectively (see supplementary fig 2 ). When we combined the findings from both appendix studies, a higher number of valine homozygous cases were observed than would be expected (6 of 18) in the genotyped appendixes compared with the overall UK population genotype frequency ${ }^{18}(\mathrm{P}=0.02$, Fisher's exact test). This increase of valine homozygous genotypes in positive appendix specimens differed from the 177 patients with vCJD, all of whom to date have been methionine homozygotes $\left(\mathrm{P}<10^{-5}\right.$, Fisher's exact test, see supplementary fig 2). ${ }^{131920}$

\section{Technical aspects of the antibodies}

On a technical aspect, our study revealed a performance difference between the antibodies used, whereby ICSM35 had a higher signal to noise ratio than either KG9, 12F10, or 3F4. This is in contrast with previous studies where $3 \mathrm{~F} 4$ and KG9 were used. The previous appendix survey ${ }^{21}$ used $3 F 4$ and KG9 but not ICSM35. All antibodies detected weak cortical PrP labelling in autopsy material (fig $2 \mathrm{D}, \mathrm{I}, \mathrm{N}, \mathrm{S}$ ) and were validated with formic acid treated tonsil biopsies (fig $2 \mathrm{E}, \mathrm{J}, \mathrm{O}, \mathrm{T}$ ). The appendix biopsy samples were material from surgery, usually rapidly and short term fixed in formalin and not treated with formic acid. It is possible that ICSM35 was more sensitive at detecting abnormal PrP in such biopsy samples and that the other three antibodies benefit from formic acid treatment after formalin fixation, as suggested in figure $1 \mathrm{E}, \mathrm{J}, \mathrm{O}, \mathrm{T}$.
Importantly, all four antibodies detected the same cell type in immunolabelled follicles of positive appendix samples.

Several studies have validated immunohistochemistry in combination with appropriate retrieval techniques as an adequate tool to detect abnormal PrP and underpin the validity and reliability of previous studies and the present study to detect abnormal PrP in archival material, ${ }^{22} 23$ despite the unavailability of antibodies specific for abnormal PrP and suitable for formalin fixed, paraffin embedded material. Importantly, these studies also concluded that lymphoreticular accumulation of abnormal PrP is a specific feature of vCJD in prion diseases in humans.

\section{Sensitivity of the tests}

For several reasons, immunohistochemically detected positivity in appendixes may underestimate the prevalence of abnormal PrP. Firstly, it is assumed that tissue in an appendix block is adequately represented by the two adjacent sections that were screened. Although under-sampling would be a problem only in those appendixes that contained positive follicular dendritic cells in one or a few follicles, such biological variation could cause our method to have reduced sensitivity and lead to an underestimate of the prevalence of abnormal PrP. Animal pathogenesis studies suggest that at early stages of the incubation period the number of positive follicles is low and increases with incubation time. ${ }^{24}$ Secondly, the proportion of positive appendixes at post-mortem examination in vCJD cases has been found to vary from 19 of $20(95 \%)^{21}$ to one of four $(25 \%)^{25}$ (see supplementary table 1). Thirdly, we confirmed by using CD21 immunostaining for follicular dendritic cell that inflammation destroys these cells, hence reducing the number of potentially positive samples (fig 1). In our series, however, only $12 \%$ of appendixes were rejected owing to inflammation (see supplementary table 2) and the absence of labelling of abnormal $\operatorname{PrP}$ in any of the acutely inflamed appendixes that were examined makes it unlikely that inflammation triggers PrP deposition. Fourthly, as with the first appendix survey, a limitation of the second survey for estimating the prevalence of asymptomatic infection and predicting future numbers of vCJD cases is that it is not known at what stage during the incubation period abnormal PrP can be detected in lymphoid tissue.

\section{Discrepancy between prevalence estimates and VCJD incidence}

To date the discrepancy is growing between the prevalence of vCJD prions observed in the exposed population and the relatively small number of patients who have developed vCJD, whatever the true sensitivity and specificity of prion specific immunohistochemistry in appendixes. The number of patients with clinically manifest vCJD (177 cases at June 2013) is well below the number suggested by the prevalence of abnormal prion, even for those who are only methionine homozygous at PRNP codon 129 (an estimated 6000 cases). Nevertheless, these data are in keeping with recent animal experiments, which suggest that the human transmission barrier for bovine spongiform encephalopathy (BSE) may be high for clinical disease but substantially lower for peripheral lymphoreticular infection. ${ }^{26}$ Although clinical disease (infection of the central nervous system with vCJD prions) may greatly favour the methionine homozygous genotype, peripheral lymphoreticular infection may be much less selective, or even favour the valine homozygous genotype (see supplementary fig 2). Therefore, the prevalence data raise several important issues. Firstly, it is not known whether hosts who are methionine-valine heterozygous or valine homozygous and carry immunopositive 
lymphoreticular tissues are protected from developing vCJD or if they will eventually develop clinical prion disease, and if so how prolonged the incubation period would be. Secondly, it is unclear the extent to which the risk of developing vCJD in someone who is methionine homozygous decreases with age at exposure and whether this decrease is so great that a perpetual asymptomatic carrier state is the result. Thirdly, it is not known whether carriers pose a risk of transmitting the disease through surgical procedure $\mathrm{s}^{27}$ or through blood and other tissue donation. Finally, it is not known whether host carriers who are methionine-valine heterozygous and valine homozygous and develop clinical prion disease will present with clinical signs of vCJD with the PrP glycotype corresponding to type $4^{22}$ (also designated type $2 b^{29}$ ). The PrP glycotype is a biochemical signature, determined by the glycosylation of specific sites of the PrP molecule which distinguishes sporadic and variant CJD. ${ }^{2}$ It is possible that the transmission of vCJD through contaminated blood into people who are methionine-valine heterozygous ${ }^{29}{ }^{30}$ also results in a type 4 (2b) glycotype characteristic for vCJD (like those with methionine homozygosity) or may it instead present with a different, novel phenotype and glycotype, as suggested by some experimental transmission studies. ${ }^{31-33}$ Some answers may come through case surveillance, especially when combined with routine testing of the PRNP codon 129 genotype, and by testing the PrP glycotype of central nervous system samples in all autopsies of patients with prion disease, regardless of their clinical presentation.

Data from blood transmission studies in sheep suggest that blood infectivity is present early in the incubation period, whatever the primary route of infection. ${ }^{34}$ If a precautionary approach is adhered to, and it is assumed that the presence in humans of abnormal PrP in lymphoreticular tissue is synonymous with blood infectivity, then the observed prevalence of abnormal prion suggests that more instances of vCJD transmission by blood transfusion should have been recognised in the United Kingdom by now. ${ }^{35}$ Should transmission by way of blood transfusion prove efficient in humans, subject to certain assumptions mathematical modelling suggests that only a small number of future vCJD cases may be expected to arise in both the methionine-valine heterozygous and valine homozygous genotypes through primary transmission. Instead, a larger number of future cases may occur as a result of secondary iatrogenic transmission in all genotypes, and should this secondary epidemic arise, it would do so over decades. ${ }^{27}$

Before concluding that the clinical course of BSE related abnormal PrP in humans must differ from that in sheep, it would be prudent to measure the prevalence of abnormal PrP in human blood. As soon as a satisfactory human blood screening test becomes available in a scalable format, such an unlinked anonymous survey should be undertaken. Meanwhile, although the discrepancy between prevalence of abnormal $\operatorname{PrP}$ in appendixes and observed cases of vCJD as a result of blood transmission suggests that the risks of transmission of vCJD by blood transfusion are low, it is unclear how many blood recipients may have subclinical disease and if their life expectancy is shorter than the incubation time. Therefore it is essential to continue research into tests to detect abnormal PrP in blood.

\section{Conclusions}

The second appendix survey has provided the most robust measure of abnormal prion prevalence to date, and has shown a wider birth cohort and all genotypes to be affected. Interpretation of these findings will be aided by a further survey, already begun, of appendix specimens surgically removed before the BSE epizootic, in the mid to late 1970s, to inform about prevalence in the absence of dietary exposure.

We thank Joanne Kilkenny and Jessica Broni (University College London Institute of Neurology) and Linda Powell, Sarah Marsh, and the Pathology Unit histology team (Animal Health and Veterinary Laboratories Agency) for histological assistance; Diane Ritchie and Linda McCardle (National CJD Research and Surveillance Unit) for their expert assistance in the staining and assessment of sections for review; Phil Minor who chaired the group advising the PHE on laboratory practice in relation to large scale abnormal prion surveys and who chaired the consensus meetings of histopathologists involved in this survey; and the participating hospitals for providing us with archival histological samples (for list of hospitals see supplementary table 4).

Contributors: ONG, SB, JL, NA, and SM conceived and designed the study. SB, YS, AR-L, CK, RD, LB, MS, PW, PB, DAH, JWI, JB, MP, and $S M$ analysed and interpreted the data. $S B$ and $N G$ drafted the article and SB, NG, JI, DH, and SM revised it critically for important intellectual content. All authors, external and internal, had full access to all of the data (including statistical reports and tables) in the study and can take responsibility for the integrity of the data and the accuracy of the data analysis. NG and SB gave final approval of the version to be published and are the guarantors.

Funding: This was an independent scientific survey commissioned and funded by the Policy Research Programme of the UK Department of Health. The views expressed are those of the authors and not necessarily those of the UK Department of Health.

Competing interests: All authors have completed the ICMJE uniform disclosure form at www.icmje.org/coi_disclosure.pdf (available on request from the corresponding author) and declare that $N G$ and $C K$ are supported by the Department of Health, and SB, JL, ARL, LB, MS, $\mathrm{PW}, \mathrm{PB}$, and $\mathrm{YS}$ were in receipt of a grant from the Health Protection agency to carry out the submitted work; SB was also supported by the Department of Health's NIHR Biomedical Research Centre's funding scheme. None of the authors has a relationship with any company that might have an interest in the submitted work in the previous three years; their spouses, partners, or children have no financial relationships that may be relevant to the submitted work; and none of the authors has non-financial interests that may be relevant to the submitted work.

Ethical approval: This study was approved by the multicentre research ethics committee (reference No 08/H0405/69). As the residual tissue specimens were screened using the unlinked anonymous technique and ethical approval was obtained, the consent of the patients from whom the tissues originated was not required.

Data sharing: A full dataset and technical appendix is available with open access in the supplementary material. This includes digital histology images that can be accessed on request from the corresponding author at s.brandner@ucl.ac.uk.

1 Collinge J, Beck J, Campbell T, Estibeiro K, Will RG. Prion protein gene analysis in new variant cases of Creutzfeldt-Jakob disease. Lancet 1996;348:56.

2 Hill AF, Desbruslais M, Joiner S, Sidle KC, Gowland I, Collinge J, et al. The same prion strain causes vCJD and BSE [letter] [see comments]. Nature 1997;389:448-50. Collinge J. Molecular neurology of prion disease. J Neurol Neurosurg Psychiatry 2005;76:906-19.

4 Hilton DA, Fathers E, Edwards P, Ironside JW, Zajicek J. Prion immunoreactivity in appendix before clinical onset of variant Creutzfeldt-Jakob disease [letter]. Lancet 1998;352:703-4.

5 Hilton DA, Ghani AC, Conyers L, Edwards P, McCardle L, Ritchie D, et al. Prevalence of lymphoreticular prion protein accumulation in UK tissue samples. J Pathol 2004;203:733-9.

6 Anderson RM, Donnelly CA, Ferguson NM, Woolhouse ME, Watt CJ, Udy HJ, et al. Transmission dynamics and epidemiology of BSE in British cattle. Nature 1996;382:779-88. Hill AF, Joiner S, Linehan J, Desbruslais M, Lantos PL, Collinge J.

Species-barrier-independent prion replication in apparently resistant species. Proc Natl Acad Sci USA 2000;97:10248-53.

8 Thackray AM, Klein MA, Aguzzi A, Bujdoso R. Chronic subclinical prion disease induced by low-dose inoculum. $J$ Virol 2002;76:2510-7.

9 Georgsson G, Adolfsdottir JA, Palsdottir A, Jorundsson E, Sigurdarson S, Thorgeirsdottir $\mathrm{S}$. High incidence of subclinical infection of lymphoid tissues in scrapie-affected sheep flocks. Arch Virol 2008;153:637-44. 


\section{What is already known on this topic}

Widespread exposure of the UK population to bovine spongiform encephalopathy prions led to the emergence of variant Creutzfeldt-Jakob disease (VCJD)

Previous studies estimated the prevalence of VCJD carrier status in the UK population through screening archival appendicectomy and tonsillectomy specimens, but results were conflicting

\section{What this study adds}

This further large scale survey of appendix tissue measured a high prevalence of abnormal prion infection, and abnormal prion protein was identified across a wider birth cohort than found previously

Genetic testing of positive appendixes for the PRNP codon 129 genotype revealed a high proportion of valine homozygotes compared with the frequency in the normal population

10 Frosh A, Smith LC, Jackson CJ, Linehan JM, Brandner S, Wadsworth JD, et al. Analysis of 2000 consecutive UK tonsillectomy specimens for disease-related prion protein. Lancet 2004;364:1260-2.

11 Clewley JP, Kelly CM, Andrews N, Vogligi K, Mallinson G, Kaisar M, et al. Prevalence of disease related prion protein in anonymous tonsil specimens in Britain: cross sectional opportunistic survey. BMJ 2009;338:b1442.

12 De Marco MF, Linehan J, Gill ON, Clewley JP, Brandner S. Large-scale immunohistochemical examination for lymphoreticular prion protein in tonsil specimens collected in Britain. J Pathol 2010;222:380-7.

13 Bell JE, Gentleman SM, Ironside JW, McCardle L, Lantos PL, Doey L, et al. Prion protein immunocytochemistry-UK five centre consensus report. Neuropathol Appl Neurobiol 1997;23:26-35

14 Tsunoda R, Nakayama M, Onozaki K, Heinen E, Cormann N, Kinet-Denoel C, et al. Isolation and long-term cultivation of human tonsil follicular dendritic cells. Virchows Arch B Cell Pathol Incl Mol Pathol 1990;59:95-105.

15 Kascsak RJ, Rubenstein R, Merz PA, Tonna DeMasi M, Fersko R, Carp RI, et al. Mouse polyclonal and monoclonal antibody to scrapie-associated fibril proteins. J Virol 1987;61:3688-93

16 Zou WQ, Langeveld J, Xiao X, Chen S, McGeer PL, Yuan J, et al. PrP conformational transitions alter species preference of a PrP-specific antibody. J Biol Chem 2010;285:13874-84.

17 Ironside JW, Bishop MT, Connolly K, Hegazy D, Lowrie S, Le Grice M, et al. Variant Creutzfeldt-Jakob disease: prion protein genotype analysis of positive appendix tissue samples from a retrospective prevalence study. BMJ 2006;332:1186-8.

18 Mead S, Uphill J, Beck J, Poulter M, Campbell T, Lowe J, et al. Genome-wide association study in multiple human prion diseases suggests genetic risk factors additional to PRNP. Hum Mol Genet 2012;21:1897-906

19 Collinge J, Sidle KC, Meads J, Ironside J, Hill AF. Molecular analysis of prion strain variation and the aetiology of 'new variant' CJD. Nature 1996;383:685-90.

20 Zeidler M, Stewart G, Cousens SN, Estibeiro K, Will RG. Codon 129 genotype and new variant CJD [letter; comment]. Lancet 1997;350:668.

21 Hilton DA, Ghani AC, Conyers L, Edwards P, McCardle L, Penney M, et al. Accumulation of prion protein in tonsil and appendix: review of tissue samples. BMJ 2002:325:633-4.

22 Hill AF, Butterworth RJ, Joiner S, Jackson G, Rossor MN, Thomas DJ, et al. Investigation of variant Creutzfeldt-Jakob disease and other human prion diseases with tonsil biopsy samples. Lancet 1999;353:183-9.

23 Hilton DA, Sutak J, Smith ME, Penney M, Conyers L, Edwards P, et al. Specificity of lymphoreticular accumulation of prion protein for variant Creutzfeldt-Jakob disease. J Clin Pathol 2004;57:300-2.
24 Ryder SJ, Dexter GE, Heasman L, Warner R, Moore SJ. Accumulation and dissemination of prion protein in experimental sheep scrapie in the natural host. BMC Vet Res 2009;5:9.

25 Joiner S, Linehan J, Brandner S, Wadsworth JD, Collinge J. Irregular presence of abnormal prion protein in appendix in variant Creutzfeldt-Jakob disease. J Neurol Neurosurg Psychiatry 2002:73:597-8.

26 Beringue V, Herzog L, Jaumain E, Reine F, Sibille P, Le Dur A, et al. Facilitated cross-species transmission of prions in extraneural tissue. Science 2012;335:472-5.

27 Garske T, Ghani AC. Uncertainty in the tail of the variant Creutzfeldt-Jakob disease epidemic in the UK. PLoS One 2010;5:e15626.

28 Hill AF, Zeidler M, Ironside J, Collinge J. Diagnosis of new variant Creutzfeldt-Jakob disease by tonsil biopsy. Lancet 1997;349:99.

29 Parchi P, Capellari S, Chen SG, Petersen RB, Gambetti P, Kopp N, et al. Typing prion isoforms. Nature 1997;386:232-4.

30 Peden AH, Head MW, Ritchie DL, Bell JE, Ironside JW. Preclinical vCJD after blood transfusion in a PRNP codon 129 heterozygous patient. Lancet 2004;364:527-9.

31 Asante EA, Linehan JM, Desbruslais M, Joiner S, Gowland I, Wood AL, et al. BSE prion propagate as either variant CJD-like or sporadic CJD-like prion strains in transgenic mice expressing human prion protein. EMBO J 2002;21:6358-66.

32 Wadsworth JD, Asante EA, Desbruslais M, Linehan JM, Joiner S, Gowland I, et al. Human prion protein with valine 129 prevents expression of variant CJD phenotype. Science 2004;306:1793-6

33 Wadsworth JD, Dalmau-Mena I, Joiner S, Linehan JM, O'Malley C, Powell C, et al. Effect of fixation on brain and lymphoreticular VCJD prions and bioassay of key positive specimens from a retrospective vCJD prevalence study. J Pathol 2011;223:511-8.

34 Houston F, McCutcheon S, Goldmann W, Chong A, Foster J, Siso S, et al. Prion diseases are efficiently transmitted by blood transfusion in sheep. Blood 2008;112:4739-45.

35 Bennett $\mathrm{P}$, Daraktchiev M. Blood-borne transmission of VCJD transmission re-examination of scenarios. DH, 2011. www.gov.uk/government/uploads/system/uploads/attachment data/file/215438/dh_129965.pdf.

\section{Accepted: 20 August 2013}

\section{Cite this as: BMJ 2013;347:f5675}

This is an Open Access article distributed in accordance with the Creative Commons Attribution Non Commercial (CC BY-NC 3.0) license, which permits others to distribute, remix, adapt, build upon this work non-commercially, and license their derivative works on different terms, provided the original work is properly cited and the use is non-commercial. See: http://creativecommons.org/licenses/by-nc/3.0/. 


\section{Tables}

Table 1/ Summary of appendix samples with positive, suspect, or non-specific immunolabelling for abnormal prion protein (PrP), by sex, geographical area, birth cohort, codon 129 genotype, and analysis of PrP positive follicles, ${ }^{*}$ and a detailed breakdown of ICSM35 immunolabelling, and number of follicles with weak (+), intermediate (++), and strong (+++) positivity $\dagger$

\begin{tabular}{|c|c|c|c|c|c|c|c|c|c|c|c|c|}
\hline \multirow[b]{3}{*}{$\begin{array}{l}\text { Case No, } \\
\text { survey No }\end{array}$} & \multicolumn{3}{|c|}{ Demographic and area information } & \multicolumn{9}{|c|}{ Analysis of PrP positive and negative follicles } \\
\hline & \multirow[b]{2}{*}{ Sex } & \multirow[b]{2}{*}{$\begin{array}{l}\text { Geographical } \\
\text { area, England }\end{array}$} & \multirow[b]{2}{*}{$\begin{array}{l}\text { Birth } \\
\text { cohort }\end{array}$} & \multirow[b]{2}{*}{$\begin{array}{c}\text { Codon } \\
129\end{array}$} & \multirow{2}{*}{$\begin{array}{l}\text { KG9‡ } \\
\text { + to +++ }\end{array}$} & \multicolumn{7}{|c|}{ ICSM35§ positivity in follicles } \\
\hline & & & & & & + & ++ & +++ & Negative & Section & $\begin{array}{c}\text { No } \\
\text { positive/all } \\
\text { follicles } \\
(\%)\end{array}$ & Fig No \\
\hline \multicolumn{13}{|l|}{$\begin{array}{l}\text { Positive } \\
\text { samples: }\end{array}$} \\
\hline \multirow[t]{3}{*}{1,13119} & \multirow[t]{3}{*}{ M } & \multirow[t]{3}{*}{ North } & \multirow[t]{3}{*}{$1946-50$} & \multirow[t]{3}{*}{ MM } & 2 & 4 & - & 6 & 5 & TS1 & \multirow[t]{3}{*}{$10 / 28(35)$} & \multirow[t]{3}{*}{$3 \mathrm{~A}$} \\
\hline & & & & & 0 & - & - & - & 4 & TS2 & & \\
\hline & & & & & 0 & - & - & - & 9 & TS3 & & \\
\hline \multirow[t]{2}{*}{2,14784} & \multirow[t]{2}{*}{$\mathrm{F}$} & \multirow{2}{*}{$\begin{array}{l}\text { South and } \\
\text { London }\end{array}$} & \multirow[t]{2}{*}{$1956-60$} & \multirow[t]{2}{*}{ VV } & 1 & - & - & 1 & 4 & TS & 2/10 (20) & $3 G$ \\
\hline & & & & & 1 & - & 1 & - & 4 & TS2 & & \\
\hline 3,15048 & M & South and & $1971-75$ & MV & 0 & 1 & 2 & 1 & 0 & TS1 & $4 / 7(57)$ & $3 \mathrm{D}$ \\
\hline & & London & & & 0 & - & - & - & 3 & TS2 & & \\
\hline & & & & & 0 & - & - & - & 0 & LS & & \\
\hline 4,16937 & M & South and & 1976-80 & MM & 2 & - & 3 & 1 & 0 & TS & 4/5 (80) & $3 B$ \\
\hline & & London & & & 0 & - & - & - & 1 & LS & & \\
\hline 5,25173 & $\mathrm{~F}$ & North & 1966-70 & VV & 0 & 3 & - & 2 & 0 & TS1 & $5 / 11(45)$ & $3 \mathrm{H}$ \\
\hline & & & & & 0 & - & - & - & 3 & TS2 & & \\
\hline & & & & & 0 & - & - & - & 3 & LS & & \\
\hline 6, 25612 & $F$ & North & $1971-75$ & MV & 0 & - & 1 & 1 & 6 & TS1 & 2/11 (18) & $3 E$ \\
\hline & & & & & 0 & - & - & - & 3 & TS2 & & \\
\hline 7,28441 & $\mathrm{M}$ & Midlands and & $1956-60$ & MV & 0 & - & 3 & - & 0 & TS1 & 25/28 (89) & $2 \mathrm{~A}, \mathrm{~B}$ \\
\hline & & & & & 0 & 1 & 1 & 1 & 1 & TS2 & & $\begin{array}{l}F, G, K \text {, } \\
\text { L, P, Q }\end{array}$ \\
\hline & & & & & 2 & 9 & 6 & 4 & 2 & LS & & \\
\hline 8,31327 & $\mathrm{~F}$ & North & 1966-70 & VV & 2 & - & - & 4 & 5 & TS1 & $4 / 11(36)$ & 31 \\
\hline & & & & & 0 & - & - & - & 0 & TS2 & & \\
\hline & & & & & 0 & - & - & - & 2 & LS & & \\
\hline 9, 32182 & $\mathrm{~F}$ & Midlands and & $1956-60$ & VV & 0 & - & 2 & - & 1 & TS1 & $12 / 15(80)$ & $3 F$ \\
\hline & & & & & 0 & - & 2 & 4 & 0 & TS2 & & $2 \mathrm{U}-\mathrm{Y}$ \\
\hline & & & & & 0 & - & 3 & 1 & 2 & TS3 & & \\
\hline 10,34039 & M & Midlands and & $1981-85$ & MM & 0 & - & - & 1 & 21 & TS1 & 1/41 (2) & \\
\hline & & & & & 0 & - & - & - & 5 & TS2 & & \\
\hline & & & & & 0 & - & - & - & 14 & LS & & \\
\hline 11,36521 & M & South and & 1966-70 & MV & 0 & - & - & - & 0 & TS1 & $1 / 4(25)$ & \\
\hline & & & & & 1 & 1 & - & - & 3 & TS2 & & \\
\hline & & & & & 0 & - & - & - & 0 & TS3 & & \\
\hline 12,38647 & $\mathrm{~F}$ & South and & $1981-85$ & MM & 0 & 1 & - & - & 2 & TS1 & 6/50 (12) & $3 C$ \\
\hline & & London & & & 0 & 2 & - & - & 2 & TS2 & & \\
\hline & & & & & 1 & - & 1 & 2 & 40 & LS & & \\
\hline 13,39047 & M & South and & 1976-80 & MM & 0 & - & - & - & 8 & TS1 & 6/16 (38) & \\
\hline & & London & & & 0 & - & 1 & - & 1 & TS2 & & \\
\hline & & & & & 0 & - & - & 5 & 1 & TS3 & & \\
\hline 14,39121 & M & South and & $1976-80$ & MM & 0 & - & - & - & 0 & TS1 & $1 / 9(11)$ & \\
\hline & & & & & 1 & - & - & 1 & 5 & TS2 & & \\
\hline
\end{tabular}


Table 1 (continued)

\begin{tabular}{|c|c|c|c|c|c|c|c|c|c|c|c|c|}
\hline \multirow[b]{3}{*}{$\begin{array}{l}\text { Case No, } \\
\text { survey No }\end{array}$} & \multicolumn{3}{|c|}{ Demographic and area information } & \multirow[b]{3}{*}{$\begin{array}{c}\text { Codon } \\
129\end{array}$} & \multicolumn{8}{|c|}{ Analysis of PrP positive and negative follicles } \\
\hline & \multirow[b]{2}{*}{ Sex } & \multirow[b]{2}{*}{$\begin{array}{l}\text { Geographical } \\
\text { area, England }\end{array}$} & \multirow[b]{2}{*}{$\begin{array}{l}\text { Birth } \\
\text { cohort }\end{array}$} & & \multirow{2}{*}{$\begin{array}{c}\text { KG9‡ } \\
\text { + to +++ }\end{array}$} & \multicolumn{7}{|c|}{ ICSM35§ positivity in follicles } \\
\hline & & & & & & + & ++ & +++ & Negative & Section & $\begin{array}{c}\text { No } \\
\text { positive/all } \\
\text { follicles } \\
(\%)\end{array}$ & Fig No \\
\hline & & & & & 0 & - & - & - & 3 & LS & & \\
\hline \multirow[t]{3}{*}{15,42181} & \multirow[t]{3}{*}{$M$} & \multirow{3}{*}{$\begin{array}{l}\text { South and } \\
\text { London }\end{array}$} & \multirow[t]{3}{*}{$1951-55$} & \multirow[t]{3}{*}{ MM } & 0 & 3 & - & - & 1 & TS1 & \multirow[t]{3}{*}{$3 / 4(75)$} & \\
\hline & & & & & 0 & - & - & - & 0 & TS2 & & \\
\hline & & & & & 0 & - & - & - & 0 & TS3 & & \\
\hline \multirow[t]{4}{*}{16,42660} & \multirow[t]{4}{*}{ M } & \multirow{4}{*}{$\begin{array}{l}\text { South and } \\
\text { London }\end{array}$} & \multirow[t]{4}{*}{$1941-45$} & \multirow[t]{4}{*}{ MM } & 1 & 1 & 2 & - & 0 & TS1 & \multirow[t]{4}{*}{$3 / 5(60)$} & \\
\hline & & & & & 0 & 1 & - & - & 1 & TS2 & & \\
\hline & & & & & 2 & 1 & - & 2 & 0 & LS1 & & \\
\hline & & & & & 1 & 1 & 1 & 1 & 2 & LS2 & & \\
\hline
\end{tabular}

Suspect

samples:

\begin{tabular}{|c|c|c|c|c|c|c|c|c|c|c|c|c|}
\hline \multirow[t]{3}{*}{ 1, 18992} & \multirow[t]{3}{*}{$\mathrm{F}$} & \multirow{3}{*}{$\begin{array}{l}\text { Midlands and } \\
\text { east }\end{array}$} & \multirow[t]{3}{*}{$1956-1960$} & \multirow[t]{3}{*}{ VV } & 0 & - & - & - & 4 & TS1 & \multirow[t]{3}{*}{$1 / 10(10)$} & \multirow[t]{3}{*}{$3 \mathrm{M}$} \\
\hline & & & & & 0 & 1 & - & - & 5 & TS2 & & \\
\hline & & & & & 0 & - & - & - & 0 & TS3 & & \\
\hline \multirow[t]{2}{*}{2,20050} & \multirow[t]{2}{*}{$U$} & \multirow{2}{*}{$\begin{array}{l}\text { South and } \\
\text { London }\end{array}$} & \multirow[t]{2}{*}{$1961-1965$} & \multirow[t]{2}{*}{ MV } & 0 & - & - & - & 0 & TS & \multirow[t]{2}{*}{$1 / 16(6)$} & \multirow[t]{2}{*}{$3 \mathrm{~K}$} \\
\hline & & & & & 0 & 1 & - & - & 16 & LS & & \\
\hline
\end{tabular}

Non-specific

staining:

\begin{tabular}{|c|c|c|c|c|c|c|c|c|c|c|c|c|}
\hline 1,15368 & $M$ & $\begin{array}{l}\text { South and } \\
\text { London }\end{array}$ & 1951-1955 & $\mathrm{MM}$ & - & - & - & - & - & - & - & $3 \mathrm{~J}$ \\
\hline 2,19878 & $U$ & $\begin{array}{l}\text { South and } \\
\text { London }\end{array}$ & 1961-1965 & $\mathrm{MM}$ & - & - & - & - & - & - & - & $3 \mathrm{~L}$ \\
\hline 3,20174 & $U$ & $\begin{array}{l}\text { South and } \\
\text { London }\end{array}$ & 1981-1985 & - & - & - & - & - & - & - & - & - \\
\hline 4, 28791 & $\mathrm{~F}$ & $\begin{array}{l}\text { South and } \\
\text { London }\end{array}$ & 1961-1965 & VV & - & - & - & - & - & - & - & $3 N$ \\
\hline 6,25655 & $\mathrm{~F}$ & North & 1971-1975 & $\mathrm{MM}$ & - & - & - & - & - & - & - & 一 \\
\hline 5,31000 & $\mathrm{~F}$ & North & 1956-1960 & - & - & - & - & - & - & - & - & - \\
\hline 6,31616 & $M$ & $\begin{array}{l}\text { Midlands and } \\
\text { east }\end{array}$ & $1976-1980$ & - & - & - & - & - & - & - & - & - \\
\hline 7,31753 & $M$ & $\begin{array}{l}\text { Midlands and } \\
\text { east }\end{array}$ & 1961-1965 & - & - & - & - & - & - & - & - & - \\
\hline 8, 34591 & $\mathrm{~F}$ & $\begin{array}{l}\text { Midlands and } \\
\text { east }\end{array}$ & $1981-1985$ & - & - & - & - & - & - & - & - & - \\
\hline 9,42713 & $\mathrm{~F}$ & $\begin{array}{l}\text { South and } \\
\text { London }\end{array}$ & $1951-1955$ & - & - & - & - & - & - & - & - & - \\
\hline
\end{tabular}

$\mathrm{MM}=$ =methionine homozygous; $\mathrm{VV}=$ =valine homozygous; $\mathrm{MV}=$ =methionine-valine heterozygous; $\mathrm{U}=$ =unknown.

Most of the specimens showed an uneven distribution of positive follicles-that is, only in one of several sections within the specimen (for example, 13119,15048 , $16937,25173,25612,31372$ ).A few showed a homogenous distribution of positive follicles across all parts of the specimen (for example, 14784,28441 or 32182 ). This distribution was independent of the intensity of staining of individual follicles.

${ }^{*}$ Number of follicles positive with KG9.

†Specimens contained transverse sections (TS) and longitudinal sections (LS) of tissue with variable numbers of positive and total follicles.

¥Mouse monoclonal antiPrP antibody KG9.

§Mouse monoclonal antiPrP antibody ICSM35. 
Table 2| Prevalence of abnormal prion protein in appendix samples from operations conducted in England between 2000 and 2012 by area, sex of patient, and five year birth cohort

North east and north west South east coast, south west, and London East Midlands and West Midlands

\begin{tabular}{|c|c|c|c|c|c|c|c|}
\hline \multirow[b]{2}{*}{ Birth cohort } & \multicolumn{2}{|c|}{ North east and north west } & \multirow[b]{2}{*}{ Female } & \multirow[b]{2}{*}{ Male } & \multirow[b]{2}{*}{ Female } & \multirow[t]{2}{*}{ est ividalanas } & \multirow{2}{*}{$\begin{array}{l}\text { Total (including unknown } \\
\text { sex) }\end{array}$} \\
\hline & Female & Male & & & & & \\
\hline $1941-45$ & $0 / 165$ & $0 / 163$ & $0 / 296$ & $1 / 286$ & $0 / 183$ & $0 / 192$ & $1 / 1420$ \\
\hline $1946-50$ & $0 / 196$ & $1 / 209$ & $0 / 401$ & $0 / 348$ & $0 / 272$ & $0 / 262$ & $1 / 1918$ \\
\hline 1951-55 & $0 / 248$ & $0 / 263$ & $0 / 474$ & $1 / 372$ & $0 / 285$ & $0 / 288$ & $1 / 2124$ \\
\hline $1956-60$ & $0 / 321$ & $0 / 316$ & $1 / 590$ & $0 / 502$ & $1 / 357$ & $1 / 389$ & $3 / 2719$ \\
\hline 1961-65 & $0 / 451$ & $0 / 420$ & $0 / 662$ & $0 / 609$ & $0 / 433$ & $0 / 493$ & $0 / 3438$ \\
\hline 1966-70 & $2 / 502$ & $0 / 554$ & 0/730 & $1 / 774$ & $0 / 512$ & $0 / 574$ & $3 / 4090$ \\
\hline 1971-75 & $1 / 524$ & $0 / 530$ & $0 / 885$ & $1 / 808$ & $0 / 520$ & $0 / 620$ & $2 / 4408$ \\
\hline 1976-80 & $0 / 594$ & $0 / 634$ & 0/1035 & $3 / 1049$ & $0 / 633$ & $0 / 640$ & $3 / 5184$ \\
\hline 1981-85 & $0 / 824$ & $0 / 864$ & $1 / 1551$ & $0 / 1417$ & 0/707 & $1 / 868$ & $2 / 7140$ \\
\hline Total & $3 / 3825$ & $1 / 3953$ & $2 / 6624$ & $7 / 6165$ & $1 / 3902$ & $2 / 4326$ & $16 / 32441$ \\
\hline
\end{tabular}




\section{Figures}

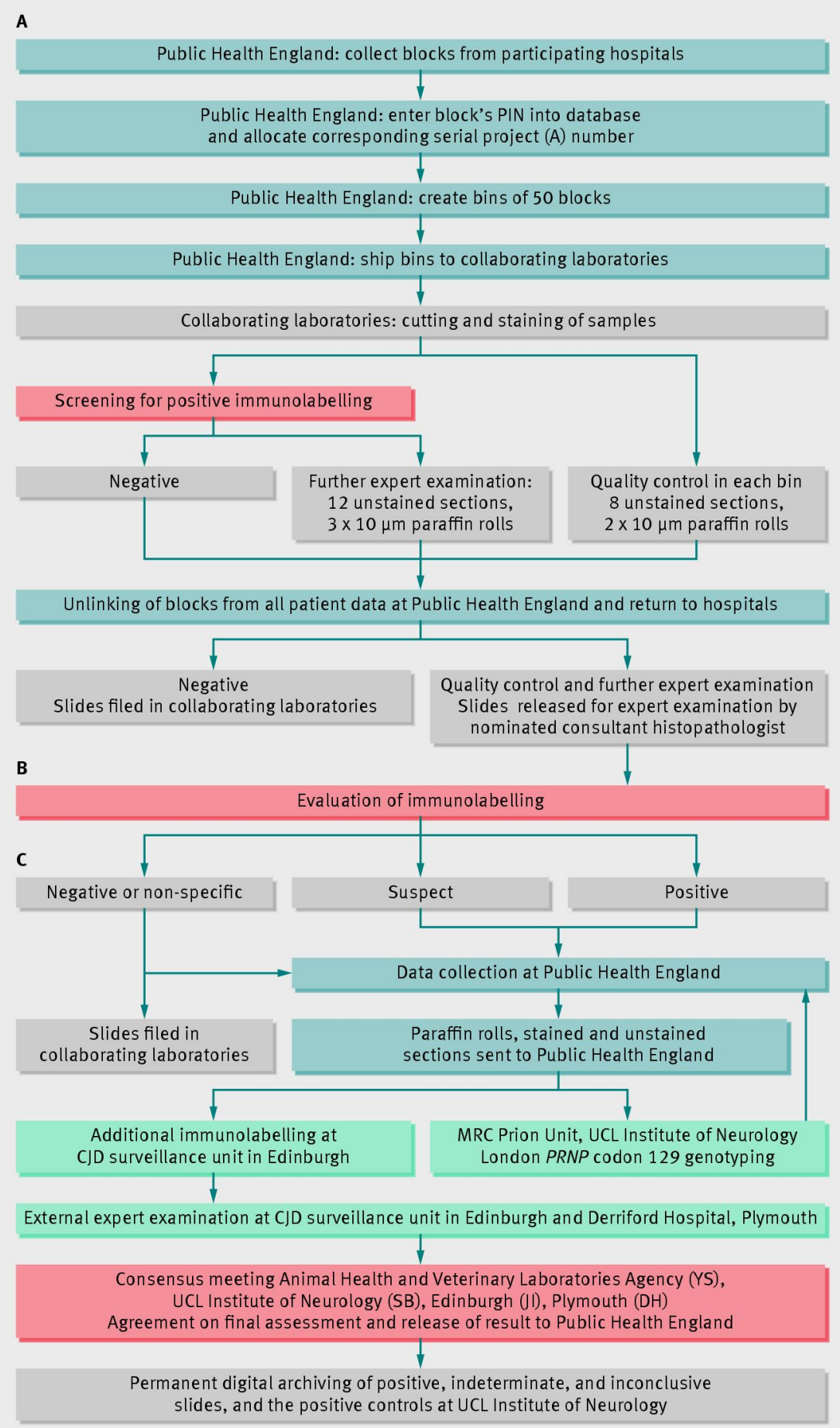

Fig 1 Process from block collection to returning blocks to participating hospitals (see supplementary file for full details) 

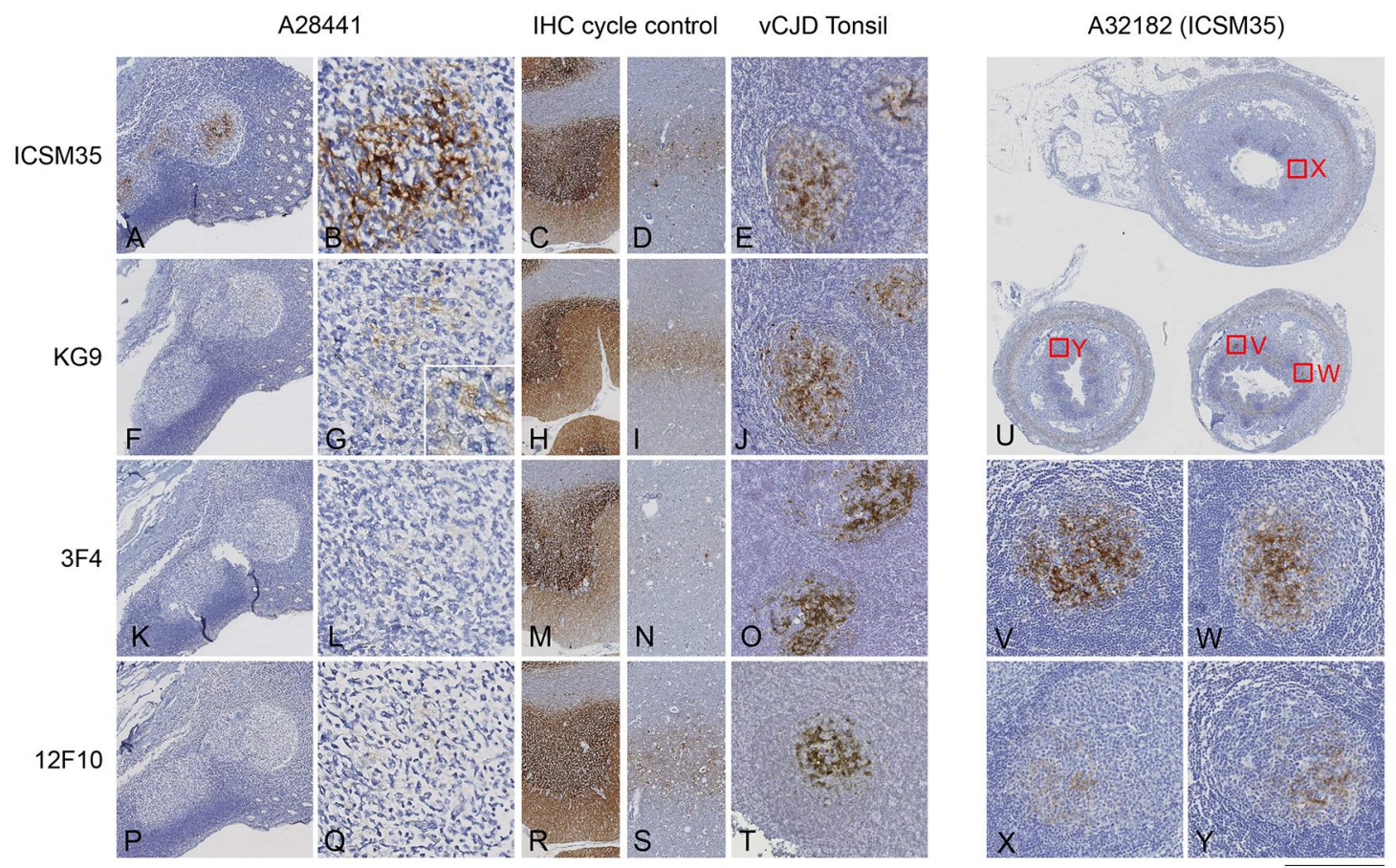

Fig 2 Immunolabelling of positive appendix samples and positive control sections stained during same machine run. First and second column: abnormal prion protein (PrP) in positive appendix sample (A28441). A, B: robust immunolabelling with antibody ICSM35 in several follicles (A). Higher magnification (B) shows characteristic labelling of follicular dendritic cells in one follicle. C, D: immunolabelling of section that served as external positive control in same machine cycle, containing section of cerebellum (C) or weak synaptic or perineuronal net labelling in the frontal cortex (D). F, G: antibody KG9 shows weaker but unequivocal immunolabelling of immediately adjacent section, whereas other antibodies (3F4, K, L) and 12F10, $P, Q)$ do not show any signal. All cerebellar sections show robust immunolabelling $(C, H, M, R)$ and there is less intense labelling of a cortical ribbon (D, I, N, S), characteristic of sporadic Creutzfeldt-Jakob disease with type 3 glycopattern. Antibody $12 \mathrm{~F} 10$ shows slightly weaker detection of cortical $\operatorname{PrP}(\mathrm{N})$. Formic acid treated tonsil biopsy shows intense immunolabelling pattern with ICSM35 and KG9. U-Y: distribution of weak, intermediate, and strong immunolabelling of positive appendix (A32182). Red squares in low power overview (Q) correspond to panel R-U. Appendix shows positive labelling in 12 of 15 follicles. U; section corresponding to TS1 (see table 1) is on top, TS2 is located bottom left, and TS3 bottom right. Scale bar corresponds to $400 \mu \mathrm{m}$ (first, third, and fourth columns; A, C, D, F, H, I, K, M, N, P, R, S), $100 \mu \mathrm{m}$ (second column, B, G, L, Q), $6 \mathrm{~mm}(\mathrm{U})$, and $200 \mu \mathrm{m}$ (vCJD tonsil column E, J, O, T and V-Y) 


\section{Immunostaining results of appendix samples}

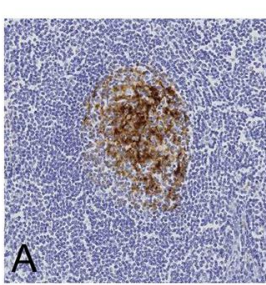

A13119 (MM)

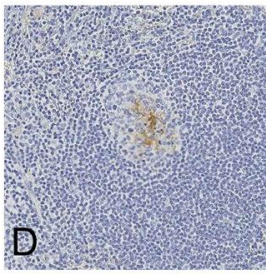

A15048 (MV)

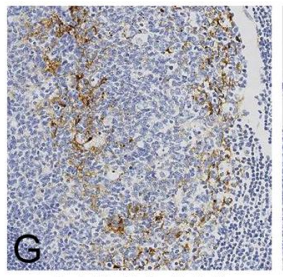

A14784 (VV)
Positive

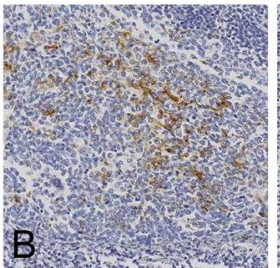

A16937 (MM)

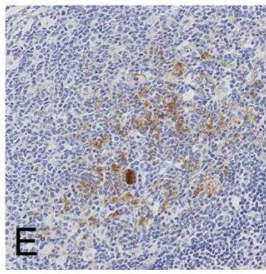

A25612 (MV)

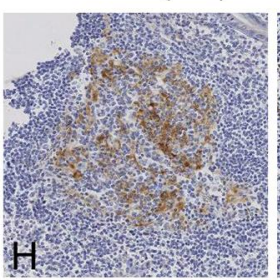

A25173 (VV)

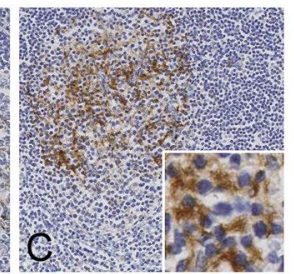

A38647 (MM)

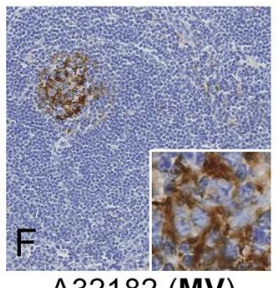

A32182 (MV)

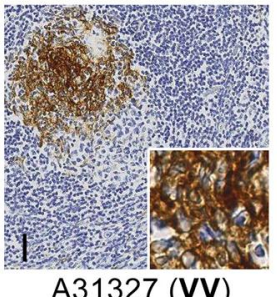

Suspect
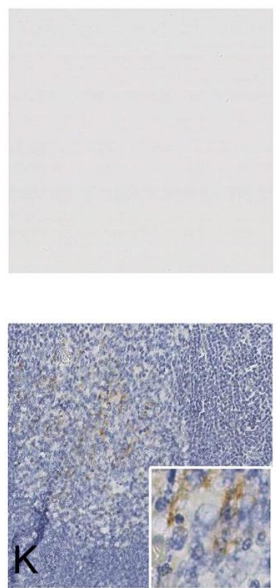

A20050 (MV)

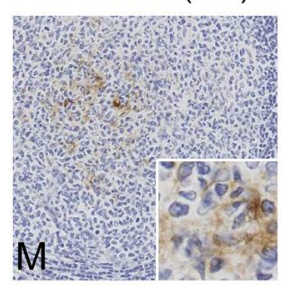

A18992 (VV)
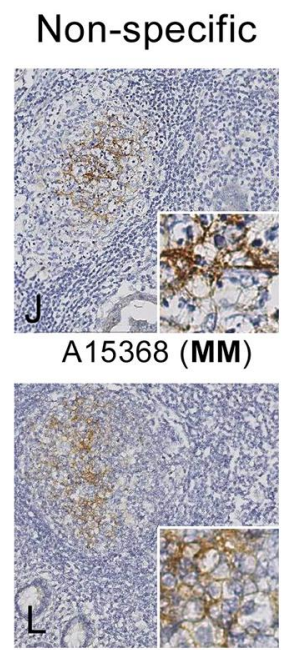

A19878 (MM)

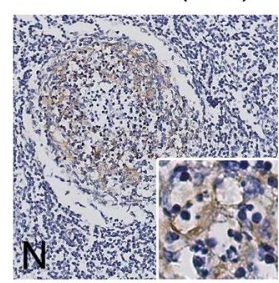

A28791 (VV)

Fig 3 Examples of appendix samples diagnosed as positive, suspect, and non-specific for abnormal prion protein (PrP). A-C: examples of positive samples with methionine homozygous genotype at PRNP codon 129. Intrafollicular distribution and intensity of PrP show some variation, and all follicles show crisp, robust staining of follicular dendritic cells. Inset in C shows area with follicular dendritic cell at high magnification. D-F: three samples with variable positive labelling, illustrating variability in size and intensity of staining. Inset in $\mathrm{F}$ shows high magnification of follicular dendritic cell in centre. G-I: positive follicular dendritic cell in cases with valine homozygous genotype at PRNP codon 129, showing similar variability as previous cases. K, M: suspect cases, showing weak labelling of structures that may correspond to follicular dendritic cell, but not confirmed in subsequent immunostains. J, L, N: non-specific cases, with antibody binding to structures in follicle centre that do not correspond to viable follicular dendritic cell. $\mathrm{J}$ and $\mathrm{N}$ are necrotic follicles where follicular dendritic cell structure has disappeared, and L shows antibody binding in an area of poor morphological preservation. Scale bar $200 \mu \mathrm{m}(50 \mu \mathrm{m}$ in insets) 